\title{
BIOCORROSION AS NA ETIOLOGICAL FACTOR OF NON-CARIOUS LESIONS: A LITERATURE REVIEW
}

\author{
Gilvânia de Jesus Freitas Leite ${ }^{1}$ \\ Lavínia Mende Santana ${ }^{2}$ \\ Isabela de Sá Oliveira ${ }^{3}$ \\ Laura Christielly Muniz Fonseca ${ }^{4}$ \\ Mychelle Percília Souza Santos ${ }^{5}$ \\ Danilo Cangussu Mendes ${ }^{6}$
}

\begin{abstract}
Aim: The present study aimed to carry out a literature review about biocorrosion as an etiological factor of non-carious lesions and dentin hypersensitivity. Method: The bibliographic search was performed in the PubMed and Virtual Health Library (VHL) databases, selecting articles published from 2015 to 2020, available in full text, in Portuguese and English, and related to the proposed theme. Results: In the studies included, it was observed that substances with low $\mathrm{pH}$, high titratable acidity, some lifestyles, and
\end{abstract}

\footnotetext{
1 Undergraduate student. State University of Montes Claros (UNIMONTES). Department of Dentistry; Prevention and Treatment of Non-Carious Cervical lesions and Dentin Hypersensitivity Project (LCNC-MOC). Montes Claros MG - Brasil. $\square$ gilvaniafreitas1l1@ gmail.com. (I) https://orcid.org/0000-0002-8374-5969.

2 Undergraduate student. State University of Montes Claros (UNIMONTES). Department of Dentistry; Prevention and Treatment of Non-Carious Cervical lesions and Dentin Hypersensitivity Project (LCNC-MOC). Montes Claros MG - Brasil. $₫$ lavinia.msantana@yahoo.com.br. https://orcid.org/0000-0002-4714-2773.

${ }^{3}$ Undergraduate student. State University of Montes Claros (UNIMONTES). Department of Dentistry; Prevention and Treatment of Non-Carious Cervical lesions and Dentin Hypersensitivity Project (LCNC-MOC). Montes Claros MG - Brasil. $\square$ isabelasa23@ hotmail.com. (1) https://orcid.org/0000-0003-2616-1796.

${ }^{4}$ Undergraduate student. State University of Montes Claros (UNIMONTES). Department of Dentistry; Prevention and Treatment of Non-Carious Cervical lesions and Dentin Hypersensitivity Project (LCNC-MOC).

Montes Claros MG - Brasil. $₫$ lauramuniz718@ gmail.com. (I) https://orcid.org/0000-0003-3293-7917.

5 Undergraduate student. State University of Montes Claros (UNIMONTES). Department of Dentistry; Prevention and Treatment of Non-Carious Cervical lesions and Dentin Hypersensitivity Project (LCNC-MOC). Montes Claros MG - Brasil. $\triangle$ mychellepercilia@gmail.com. (D) https://orcid.org/0000-0001-9036-4972.

${ }^{6}$ Professor. DDS, MS, PhD. State University of Montes Claros (UNIMONTES). Department of Dentistry; Prevention and Treatment of Non-Carious Cervical lesions and Dentin Hypersensitivity Project (LCNC-MOC). Montes Claros MG - Brasil. $\square$ danilo.mendes@unimontes.br. (1) https://orcid.org/0000-0003-4766-0009.
}

\begin{tabular}{l|ll} 
Recebido em & Aceito em & Publicado em
\end{tabular}

08/03/2021 18/08/2021 03/09/2021


occupational habits are factors that can directly interfere with dental demineralization. As a consequence of this process, non-carious lesions and dental hypersensitivity have increased their incidence. Conclusion: The main sources of acids that attack dental structure are food and beverages and endogenous acids of gastric content. Thus, it must be considered the multifactorial character of this process and the association with other etiological factors, such as tension and friction in the development of non-carious lesions, aiming to restore oral health to the patient.

Keywords: Tooth erosion; Dentin sensitivity; Tooth wear.

\section{INTRODUCTION}

The loss of hard tooth structure is a prevalent condition in clinical dental practice. This process may be physiological or pathological without any bacterial involvement. When the process is due to chewing or interdental contacts, it is classified as physiological, which can be reversible due to the remineralizing action of the saliva. On the other hand, the pathological condition is the irreversible wear on the tooth structure involving multifactorial causes ${ }^{1-3}$.

Among the etiological factors associated with pathological demineralization, biocorrosion is one of the most important. In the literature it is also called as erosion, however, this term may be considered inappropriate because it is a physical phenomenon that degrades structures through friction caused by liquid movements. Biocorrosion, on the other hand, is a more comprehensive terminology, since it encompasses all chemical, biochemical and electrochemical forms of loss of structure in living tissue ${ }^{4}$.

The biocorrosive process is characterized by the chemical dissolution of teeth due to continuous exposure to acids of intrinsic (endogenous) origin, such as gastric juice and proteolytic enzymes in the crevicular fluid; and extrinsic (exogenous), found in the composition of acidic drinks and foods, citrus fruits and medicines. When teeth are exposed to substances with a critical $\mathrm{pH}$ for the enamel (less than 5.5) for prolonged periods, there is a degradation of the structure, which can lead to pathological conditions, such as dentin hypersensitivity and non-carious lesions ${ }^{4.5}$.

In recent years, there has been an increasing increase in the prevalence of biocorrosion, associated with functional, aesthetic, and tooth sensitivity problems ${ }^{6}$. This highlights the importance of this work, which came from studies carried out in the theoretical 
modules of the Project for the Prevention and Treatment of Non-Carious Cervical Injuries and Dentin Hypersensitivity (LCNC-MOC) of the State University of Montes Claros-MG. The theoretical reflection on the subject is justified due to its practical applicability in dental care clinics for patients. Therefore, the objective of this work is to carry out a literature review about biocorrosion as an etiological factor of non-carious cervical lesions and dentin hypersensitivity.

\section{METHOD}

This integrative literature review aims to identify scientific productions that address the biocorrosive process as an etiological factor of dentin hypersensitivity and noncarious lesions. The bibliographic search was performed by two authors, in July 2020, in the databases PubMed and Virtual Health Library (VHL). The Health Sciences Descriptors (DeCS) dental erosion, dentin sensitivity, tooth wear, and etiology were combined using the Boolean connector "and", in Portuguese and English, in order to find a greater number of productions, avoiding that some important study was excluded from the survey.

Articles in English and Portuguese, published from 2015 to 2020, available in full and related to the objective of the work, addressing the association of dental wear with acid diet and endogenous acidity were included in the search. Studies that were not related to the topic, with unavailable access, duplicated between databases, in other languages, case reports, interviews, and master's or doctoral theses were excluded.

In the search, 307 articles were found, 269 in the PubMed database and 38 in the VHL. The first selection step was performed by reading the titles and abstracts of all identified articles. Subsequently, the selected studies were analyzed in full, which made it possible to exclude other texts that did not meet the review proposal. Finally, 21 articles from PubMed and 2 from the VHL were included, in addition to other studies selected manually because they are considered classics in the literature regarding the topic (figure 1). 


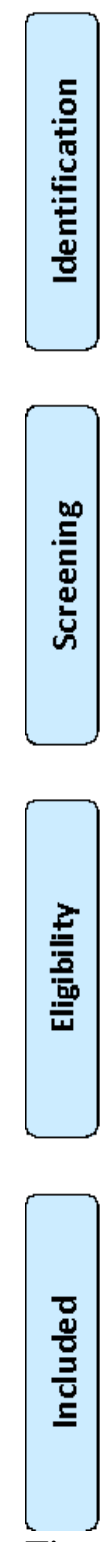

Records identified through Pubmed searching $(\mathrm{n}=269)$
- Records identified through

VHL searching

$(\mathrm{n}=38)$


Studies included in

synthesis

$(\mathrm{n}=26)$

Figure 1: Fluxogram for the selection of articles.

\section{RESULTS AND DISCUSSION}

\section{Mechanism of action of acids on tooth structure}

Several studies show an association between acidic substances and dental biocorrosion, correlating this etiological factor with processes that affect the structural and functional integrity of teeth $1,4,7,8$. Thus, it is important to understand the mechanisms of action 
of acids on the dental structure to ensure adequate diagnosis and treatment, mitigating the impacts on the quality of life of individuals ${ }^{4,7}$.

Chemical degradation occurs through the action of $\mathrm{H}^{+}$ions in contact with the dental structure. $\mathrm{H}^{+}$ions bind to the components of hydroxyapatite, releasing calcium $\left(\mathrm{Ca}^{2+}\right)$ and phosphate $\left(\mathrm{HPO}_{4^{-2}}\right)$ in the environment (Figure 2). Depending on the characteristics of the acid, demineralization can occur mildly or aggressively. In this process, there is also interference from the protective factor of saliva, due to its buffering capacity, neutralizing acidic agents ${ }^{1,910}$.

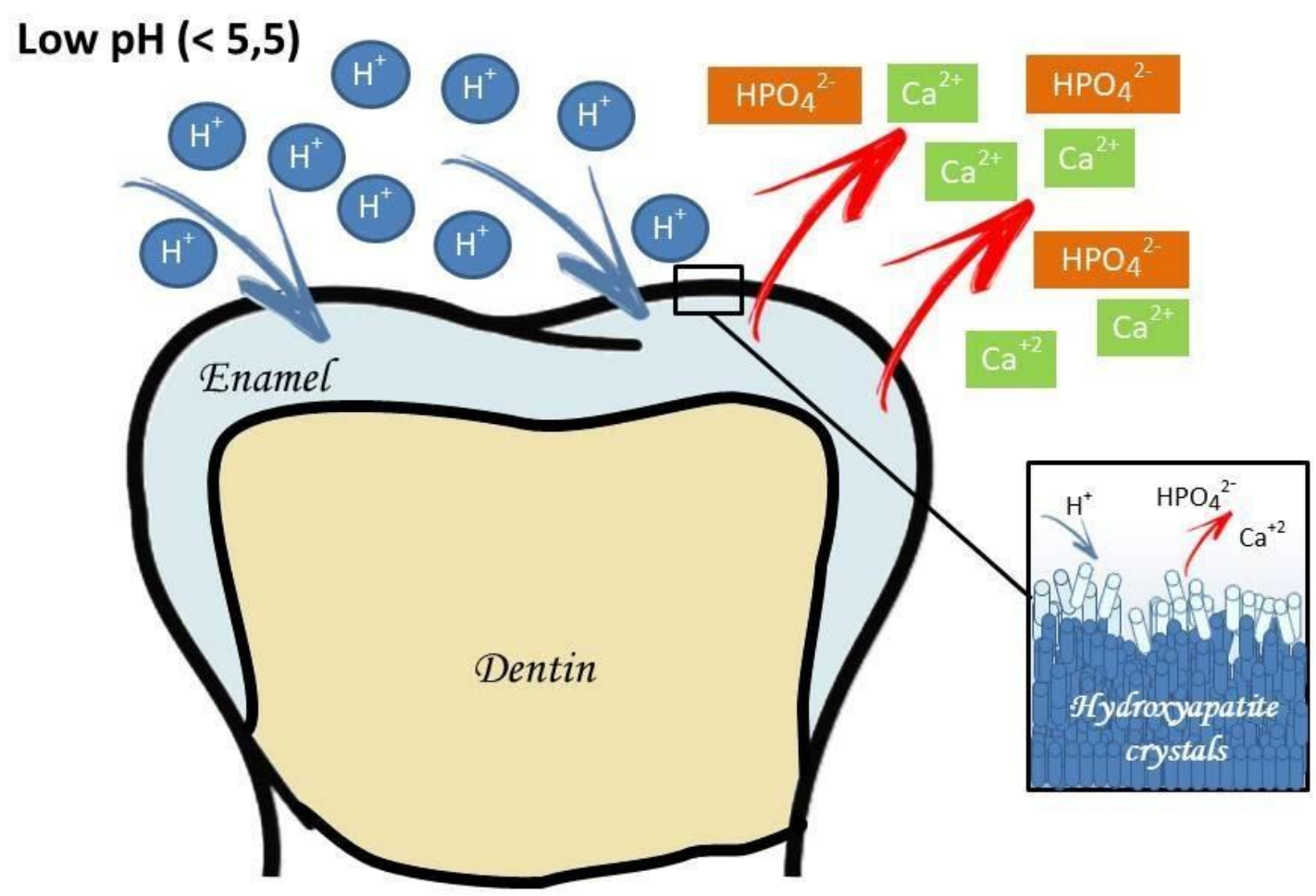

Figure 2: Tooth demineralization in the presence of acidic substances with low ph. When the ph decreases to below 5.5, undersaturation with respect to hydroxyapatite is reached resulting in mineral dissolution. Hydrogen ions combine with carbonate, phosphate, or both in the hydroxyapatite crystals, and release the mineral ions in the environment. Besides, the acidic anions may act by chelating calcium from the crystal surface.

Source:Authors 
Biocorrosion occurs initially in the enamel with the degradation of the surface components, which results in increased roughness and allows the acid to diffuse through the prisms, leading to dentin exposure. Clinically, it is possible to perceive this process when the potential for salivary neutralization is less than the acid frequency and intensity. Dentin is more susceptible and a $\mathrm{pH}$ of around 6.0 is already capable of reaching the peritubular and intertubular junction, enlarging the tubules and exposing collagen fibers, leading to hypersensitivity 1.8 .9 .

To identify the biocorrosive potential of an acid, its chemical properties, such as $\mathrm{pH}$ value, titratable acidity, and buffering capacity must be evaluated. The $\mathrm{pH}$ is related to the concentration of $\mathrm{H}^{+}$available in the environment. The titratable acidity is considered the best way to measure acid aggressiveness "because it indicates the actual availability of $\mathrm{H}^{+}$capable of damaging the dental surface. On the other hand, the buffering capacity refers to the amount of basic ions that a buffer solution can absorb, without significantly changing its $\mathrm{pH}{ }^{12}$.

Some acids such as phosphoric, citric, malic, and tartaric are found in foods and drinks widely consumed by individuals. They have high biocorrosive potential, varying according to frequency, time of consumption and method of ingestion. An acidic diet has a greater destructive power at night, since at this time the salivary flow is reduced, which increases the risk of hypersensitivity and the appearance of non-carious lesions. ${ }^{11,13,14}$

\section{Influence of $\mathrm{pH}$ in the biocorrosive process}

Chemical factors such as $\mathrm{pH}$, present in the substances, directly interfere with the intensity of the acidic dissolution of the tooth. A pH less than 5.5 is capable of causing significant loss of enamel surface hardness, making it soluble by the amount of hydrogen ions in the medium. Carbonated drinks, Gatorade, kiwi, lemon, and orange juices showed low $\mathrm{pH}$ values and greater demineralization, confirming the interference of hydrogen potential in biocorrosion ${ }^{15}$.

A study conducted by Jameel et al. (2016) ${ }^{11}$ analyzed teeth exposed to low pH substances $(<5.5)$ and observed the presence of marked signs of demineralization, such as cracks, rough surfaces, irregularities, dissolution of enamel prisms and areas between dentinal tubules. In addition, dental surfaces exposed to an acidic environment gradually lose their 
hardness and increase the enamel porosity. Clinically, it was possible to verify softened and opaque surface, proving the influence of $\mathrm{pH}$ on the dissolution of mineralized tissue ${ }^{16}$.

Wegehaupt et al. (2016) ${ }^{17}$ investigated the erosive potential of effervescent vitamin and mineral tablets. These products have in their composition organic acids (citric, tartaric, malic) with low $\mathrm{pH}$ (3.82 to 4.49), which can induce dental demineralization. Besides, they found that the presence of calcium in the tablets is a protective factor that may influence the biocorrosive potential. A high concentration of calcium contributed to less demineralization than tablets with similar $\mathrm{pH}$, but which have a low amount of calcium.

Drinks and foods with $\mathrm{pH}$ less than 4.4 cause loss of tooth structure to a greater or lesser degree. The consumption of acids with higher concentrations of available hydrogen ions results in immediate dissolution of the tooth surface, making it susceptible to removal by other factors, such as tension and friction. The $\mathrm{pH}$ measurement is the main way to check the acid's ability to cause immediate demineralization of the tooth structure. Titratable acidity is another measure, however, it does not assess the erosive potential as the $\mathrm{pH}$, due to the limited time of exposure with the ingested liquids and swallowing ${ }^{13}$. Table 1 shows the $\mathrm{pH}$ of some products commonly consumed in the contemporary lifestyle of the population.

Table 1 - pH information of frequently consumed substances.

\begin{tabular}{llll}
\hline Substance & $\mathbf{p H}$ & Substance & $\mathbf{p H}$ \\
\hline Coca-Cola & 2,55 & Red Bull & 3,35 \\
Coca-Cola Zero & 2,96 & Gatorade & 2,89 \\
Sprite & 2,57 & Ice tea & 2,43 \\
Guaraná Antartica & 2,62 & Forest berries yoghurt & 4,13 \\
Carbonated water & 5,25 & Mucosolvon (medicine) for children & 3,13 \\
Apple juice & 3,24 & Coffee & 4,50 \\
Orange juice & 3,63 & Trident gum & 2,74 \\
Lemon juice & 2,25 & Vitamin C (tablet) & 4,02 \\
\hline
\end{tabular}

Source: LUSSI et al. (2015); RAFEY et al. (2016); FLORIAN et al., 2016; REDDY et al., 2016.

\section{Lifestyle and occupational risks}

The etiology of biocorrosion may have as a risk factor some professions and lifestyles that are directly linked to contact with acidic substances and foods that, depending on the frequency, duration and intensity, can lead to tooth wear ${ }^{1.18}$. 
3.3.1. Wine tasters: They are exposed to chemical degradation of the teeth due to this product having a low $\mathrm{pH}$ and containing acids, such as malic. In addition, at the time of tasting, the wine remains in contact with the tooth surface for a long time, which increases the risk of demineralization ${ }^{1,18}$.

3.3.2. Industry workers: When exposed to industrial gases, especially those emitted in the fertilizer and battery factories, they become more susceptible to biocorrosion. However, with the use of equipment and protective measures, this risk decreases ${ }_{1.18}$.

3.3.3. Athletes: Dehydration due to physical activity reduces salivary flow and, to replace electrolytes, many of these professionals use energy drinks with a high biocorrosive potential. With the association of these factors, the effects can be even more significant. Some athletes also show bruxism events, like teeth clenching, during the practice of physical activities, increasing the tooth wear ${ }^{1,18}$. Grippo, Simring and Coleman (2012) ${ }^{19}$ have already mentioned that chemical and biochemical activity is accelerated in the presence of stress.

3.3.4. Professional swimmers: To reduce the contamination of swimming pool water, an additive widely used is chlorine, which gradually dissociates into hypochlorous acid, lowering the $\mathrm{pH}$ of the water (around 3.7). This includes swimmers in the risk group for biocorrosion, as they are exposed for a long time in an acidic environment ${ }^{10,18}$.

3.3.5. Healthy lifestyle and diet: The adoption of a healthy lifestyle and vegetarian diets has great relevance for the control of several systemic diseases and for physical wellbeing, however, it can harm the health of the teeth. Frequent and excessive intake of fruits, spices, vegetables, acidic juices, sauces and vinegar, predisposes to the dissolution of the tooth surface, which can lead to dentin hypersensitivity and the formation of non-carious lesions ?

\section{Interference of endogenous acids in the biocorrosive process}

The main source of intrinsic acid is gastric content, whose $\mathrm{pH}$ is very low $(\mathrm{pH} \cong 2$ ) and highly biocorrosive. In addition to the low $\mathrm{pH}$, the gastric content also present proteolytic enzymes from the stomach (pepsin) and the pancreas (trypsin) in addition to those present in the crevicular fluid (Figure 3). These enzymes can come into contact with the oral cavity through vomiting, reflux or regurgitation. Thus, they are usually not found in the oral cavity, but when together they cause greater degradation of the dental structure than when present in 
isolation. This is because trypsin makes the collagen matrix more susceptible to degradation by pepsin due to the opening of binding sites for this enzyme, so a greater degradation will occur when they act together ${ }^{18,20}$.

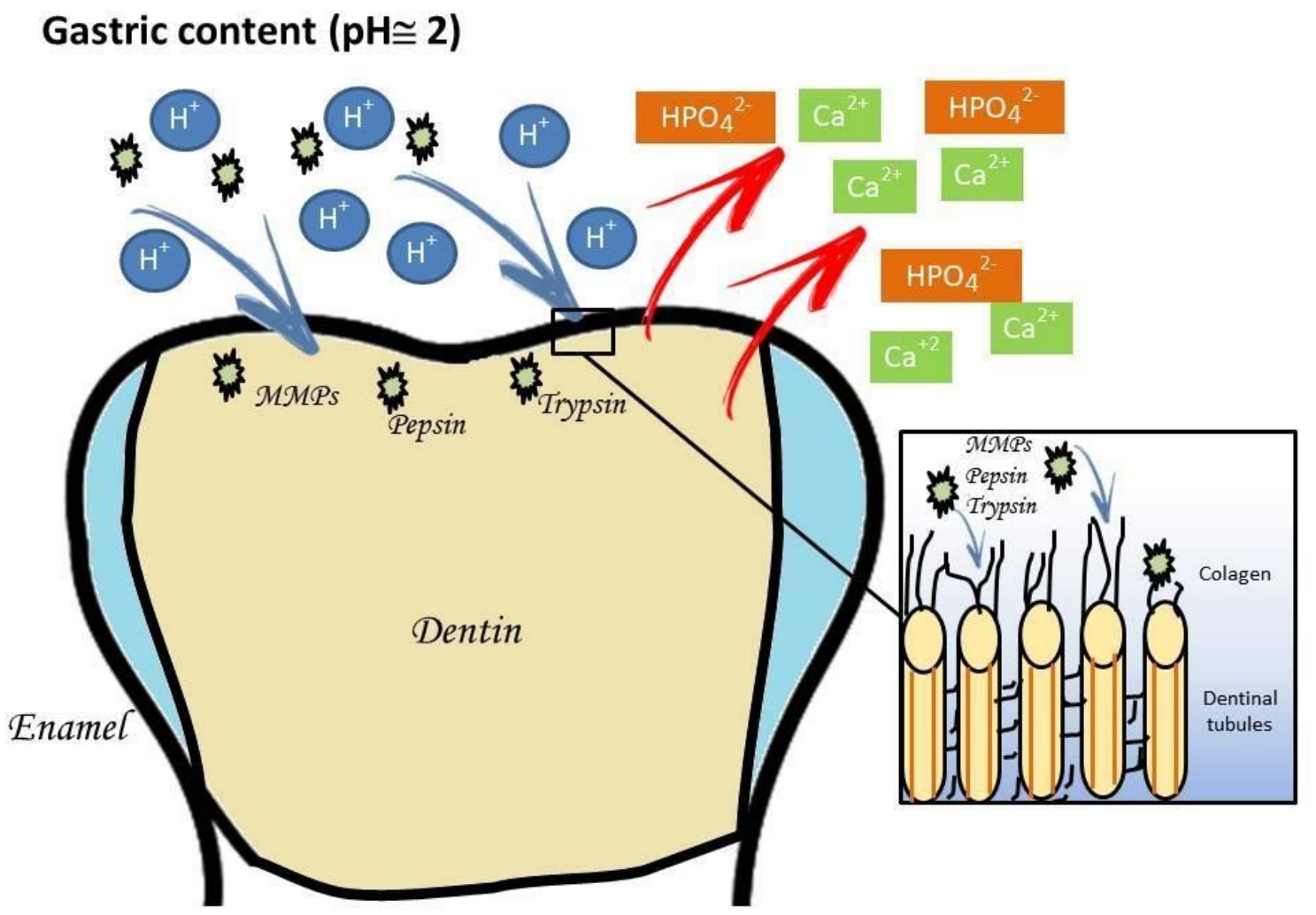

Figure 3: Biocorrosive demineralization of dentin in the presence of endogenous acid. The hydroxyapatite crystals in dentin are demineralized by the same way that occurs in enamel. When collagen is exposed it is digested by proteolytic enzymes from the stomach (pepsin), the pancreas (trypsin), and those present in the crevicular fluid (Matrix metalloproteinases MMPs). This process occurs quickly because of the lower dissolution resistance of dentin when compared to enamel.

Source:Authors

Some physiological or pathological changes are associated with biocorrosive episodes caused by hydrochloric acid, such as indigestion, heartburn, epigastric pain, chronic cough, gastroesophageal reflux disease, pregnancy, obesity, bulimia and anorexia. In addition, chronic alcoholism is associated with dental demineralization, since alcoholic beverages have 
acidic components and, frequent consumption, can lead to heartburn, episodes of vomiting and reduced saliva buffering capacity ${ }^{1,7,21,22}$.

\section{Action of the biocorrosive process of acids and dentin hypersensitivity}

Dentin hypersensitivity (HD) can be defined as a short and acute pain that normally occurs due to exposure of dentin tubules to thermal, physical or chemical stimuli. The constant and intense action of acids leads to the loss of dental hard tissue, which can generate non-carious lesions. When this demineralization occurs together with gingival recession, generally dentin hypersensitivity is present. This process can be aggravated when the dissolution is derived from acids of endogenous origin, such as gastric juice which, in addition to the low $\mathrm{pH}$, contains proteolytic enzymes that enhance the biocorrosive effect ${ }^{23-}$ 25 .

A study by Rao et al. (2019) ${ }^{25}$ investigated the experience of dentin hypersensitivity in swimmers. The prevalence of non-carious lesions with biocorrosion characteristics was high. Besides, professionals who spent more than two hours a day in training or frequently consumed energy and carbonated drinks had a higher number of lesions. Participants also reported that the consumption of citrus and cold products aggravated dentin hypersensitivity and the most common place of discomfort was the upper anterior region, showing the interference of acid demineralization in the etiology of HD.

\section{Characteristics of non-carious lesions due to biocorrosion}

Non-carious lesions (NCLs) resulting from the loss of tooth structure by biocorrosive action can present characteristics that compromise aesthetics, function, and even pulp vitality. These lesions are more common in the buccal surface when the acid is exogenous, while incisal, palatal, and occlusal areas are more common when endogenous acid is involved. The tooth surface becomes thinner, smoother, brighter and yellowish. In the early stages of NCLs, dentin hypersensitivity is frequently observed ${ }^{18,26}$.

Initially, acid aggression causes a smooth surface, glazed appearance, increased translucency and tendency to fracture of the incisal edges in the dental structure. Then, the lesions become rounded, shallow and flat. In posterior teeth it can occur dentinal exposure, rounded cusps and concavities. In severe cases, the whole occlusal or facial morphology may 
disappear. If exposure to acids is not contained, triggering pulp responses with the formation of reactive dentin, leading to the obliteration of the tubules. When the acidic dissolution is greater than the repair capacity of the dentin-pulp complex, it may result in pulp exposure ${ }^{27}$. Biocorrosion lesions can be distinguished from those caused predominantly by tension, because the last one shows a wedge-shaped aspect, with a sharp margin in the coronal part and cuts at right angles into the enamel surface ${ }^{28}$.

\section{CONCLUSION}

This literature review shows that dental demineralization associated with biocorrosion has become a prevalent condition with great clinical relevance in recent years. This increase in the population has been reported to the relationship with the patient's lifestyle. The evolution of the biocorrosion lesions is determined by the association of factors such as $\mathrm{pH}$, food acidity, occupational risks and the action of intrinsic acids. Therefore, the multifactorial etiology must be studied and understood by dental surgeons and multidisciplinary teams in order to guide, prevent, treat and restore patients' oral health.

\section{REFERÊNCIAS}

1. Warreth A, Abuhijleh E, Almaghribi MA, Mahwal G, Ashawish AJTSdj. Tooth surface loss: A review of literature. 2020;32:53-60.

2. Twetman S. The evidence base for professional and self-care prevention-caries, erosion and sensitivity. BMC oral health: Springer; 2015. p. S4.

3. Rusu Olaru A, Popescu Mr, Dragomir lP, Popescu DM, Arsenie CC, Rauten AM. Identifying the Etiological Factors Involved in the Occurrence of Non-Carious Lesions. Curr Health Sci J 2019;45:227-34.

4. GRIPPO JO, Simring M, Coleman TA. Abfraction, abrasion, biocorrosion, and the enigma of noncarious cervical lesions: A 20-year perspective. 2012;24:10-23.

5. Monagas J, RitwiK P, Kolomensky A, et al. Rumination Syndrome and Dental Erosions in Children. J Pediatr Gastroenterol Nutr 2017;64:930-2.

6. SKalsky JaRKANDER M, GRINDEFJORd M, CARLSTEDT K. Dental erosion, prevalence and risk factors among a group of adolescents in Stockholm County. Eur Arch Paediatr Dent 2018;19:23-31. 
7. Kontaxopoulou I, Alam S. Risk Assessment for Tooth Wear. Prim Dent J 2015;4:25-9.

8. Milosevic A. Acid Erosion: An Increasingly Relevant Dental Problem. Risk Factors, Management and Restoration. Prim Dent J 2017;6:37-45.

9. Moda MD, Fagundes TC, Bresciani E, Briso ALF, Dos Santos PH. Comparison of in vitro erosion protocols in bovine teeth to simulate natural erosion lesion: analysis of mechanical properties and surface gloss. J Appl Oral Sci 2019;27:e20180107.

10. Marques Martinez L, Leyda Menendez AM, Ribelles Llop M, Segarra Ortells C, Aiuto R, GARCOVich D. Dental erosion. Etiologic factors in a sample of Valencian children and adolescents. Cross-sectional study. Eur J Paediatr Dent 2019;20:189-93.

11. JAMEEL RA, KHAN SS, RAHIM ZHA, BAKRi MM, SidDiQUi SJJPMA. Analysis of dental erosion induced by different beverages and validity of equipment for identifying early dental erosion, in vitro study. 2016;66:843-8.

12. SoARES PV, GRIPPO JO. Noncarious Cervical Lesions and Cervical Dentin Hypersensitivity Etiology, Diagnosis, and Treatment. 1 ed: Quintessence Publishing; 2017.

13. RedDy A, Norris DF, MOMEni SS, WALDo B, Ruby JD. The pH of beverages in the United States. J Am Dent Assoc 2016;147:255-63.

14. Al-Dlaigan YH, Al-Meedania LA, AnIL S. The influence of frequently consumed beverages and snacks on dental erosion among preschool children in Saudi Arabia. Nutr J 2017;16:80.

15. LUSSI A, CARVALHO TSJPO. Analyses of the erosive effect of dietary substances and medications on deciduous teeth. 2015;10:e0143957.

16. RAJEev G, Lewis AJJJoC, Dentistry E. A time based objective evaluation of the erosive effects of various beverages on enamel and cementum of deciduous and permanent teeth. 2020;12:e1.

17. Wegehaupt FJ, Lunghi N, HogGer VM, AtTin T. Erosive potential of vitamin and vitamin+mineral effervescent tablets. Swiss Dent J 2016;126:457-65.

18. Peumans M, Politano G, Van Meerbeek B. Treatment of noncarious cervical lesions: when, why, and how. Int J Esthet Dent 2020;15:16-42. 
19. GripPo JO, Simring M, Coleman TA. Abfraction, abrasion, biocorrosion, and the enigma of noncarious cervical lesions: a 20-year perspective. J Esthet Restor Dent 2012;24:10-23.

20. FRIESEN LR, BOHATY B, ONIKUL R, et al. Is histologic esophagitis associated with dental erosion: a cross-sectional observational study? BMC Oral Health 2017;17:116.

21. Ganesh M, Hertzberg A, Nurko S, Needleman H, Rosen R. Acid Rather Than Nonacid Reflux Burden Is a Predictor of Tooth Erosion. J Pediatr Gastroenterol Nutr 2016;62:309-13.

22. Wilder-Smith CH, Materna A, Martig L, Lussi A. Longitudinal study of gastroesophageal reflux and erosive tooth wear. BMC Gastroenterol 2017;17:113.

23. Longridge NN, Youngson CCJPDJ. Dental Pain: Dentine Sensitivity, Hypersensitivity and Cracked Tooth Syndrome. 2019;8:44-51.

24. Alcantara PM, Barroso NFF, Botelho AM, Douglas-De-Oliveira DW, GONCALVES PF, FLECHA OD. Associated factors to cervical dentin hypersensitivity in adults: a transversal study. BMC Oral Health 2018;18:155.

25. RaO KA, Thomas S, Kumar JK, NARAyAn V. Prevalence of Dentinal Hypersensitivity and Dental Erosion among Competitive Swimmers, Kerala, India. Indian J Community Med 2019;44:390-3.

26. AriYanayagam Y. A Dental Hygienist's and Therapist's Guide to the Management of Tooth Erosion. Prim Dent J 2016;5:58-62.

27. Muller-Bolla M, Courson F, SMail-Faugeron V, Bernardin T, Lupi-Pegurier L. Dental erosion in French adolescents. BMC Oral Health 2015;15:147.

28. Magalhaes AC, Wiegand A, Rios D, Honorio HM, Buzalaf MA. Insights into preventive measures for dental erosion. J Appl Oral Sci 2009;17:75-86. 